\title{
Physicochemical properties and heavy metals leachability of fly ash from coal-fired power plant
}

\author{
Xiang Wei ${ }^{\mathrm{a}, \mathrm{b}, *}$, Han Baoping ${ }^{\mathrm{a}, \mathrm{c}}$, Zhou Dong ${ }^{\mathrm{d}}$, Nzihou Ange ${ }^{\mathrm{b}}$ \\ ${ }^{a}$ School of Environment Science and Spatial Informatics, China University of Mining E Technology, Xuzhou 221116, China \\ ${ }^{\mathrm{b}}$ Centre RAPSODEE, Mines Albi, University of Toulouse, Albi 81013, France \\ ${ }^{\mathrm{c}}$ Xuzhou Institute of Technology, Xuzhou 221008, China \\ ${ }^{\mathrm{d}}$ Beijing Puresino-Boda Environmental Engineering Co., Ltd., Beijing 100082, China
}

\begin{abstract}
A B S T R A C T
The physicochemical properties of fly ash from two kinds of coal-fired power plants were studied. Three aspects were examined: the micro-morphology, the mineral composition and the content of heavy metals. The results show that the fly ash from plants using a circulating fluidized bed are more irregular particles, while the particles from the plants using a pulverized coal-fired boiler are mainly spherical in shape. Quartz and mullite are the main crystalline phases in the ash. Clearly, both the technology and the coal used by a power plant can influence the mineral composition of the ash. The mineral composition of fly ash from a circulating fluidized bed is more complex than that from a pulverized coal-fired boiler. The quantity of elements found in the fly ash is greater than that found in the bottom ash for the same plant. Heavy metals are likely to be enriched in the fly ash. Heavy metal leachability was studied using two leaching methods. The results indicate that most of the heavy metals that leached during either batch leaching or column leaching experiments did not exceed the related maximum concentration standards. But Ni concentrations in the leachates from both batch and column tests exceed the standard. The highest excess rates in both tests were $572 \%$ and $497 \%$, which levels might threaten the environment.
\end{abstract}

Keywords:

Fly ash

Physicochemical property

Leachability

Heavy metal

\section{Introduction}

Coal fly ash is the by-product of coal-fired power plants that use flue-gas desulfurization technology. Ash consists of both fly ash and bottom ash, which constitute about $25 \%$ and $75 \%$, respectively of the total ash [1-3].

Many studies have shown that most fly ash consists of silicates, along with unburnt carbon and/or char. The mineral composition is quartz and feldspar and the ash is rich in trace metals [4-7]. Mastering the mineral composition, morphology, heavy metals content and chemical composition of the fly ash is essential for developing its utilization.

Fly ash contains trace heavy metals. If the fly ash is piled outside and comes in contact with rain or other water, the heavy metals will leach from the fly ash and contaminate the soil, groundwater, or surface water. Leaching tests can help establish the leachability and mobility of the heavy metals from the fly ash and help predict the environmental impact associated with ash pond disposal techniques [8].

Skodras studied the chemical, leaching and toxicity characteristics of circulating fluidized bed combustion residues in Greece [9].

\footnotetext{
* Corresponding author. Tel.: +86 51687721817

E-mail address: xiangwei0229@163.com (W. Xiang).
}

The results showed that toxic trace elements preferentially concentrated in the fly ash particles, since they presented a smaller particle size. Wang investigated the leaching behavior and potential environmental impact of the 11 potentially hazardous elements found in coal combustion residues [10]. A similar leaching behavior from both fly and bottom ash was observed. Souhail analyzed the leaching behavior of heavy metals from a mineral processing waste (MPW) [11]. Batch and column leaching tests were conducted on ground MPW, for different liquid/solid ratios and $\mathrm{pH}$ values, to determine the metal release mechanisms.

In this study, the physicochemical properties of fly ash were analyzed in three aspects: micromorphology, mineral composition and the content of heavy metals. Batch (equilibrium) and column (dynamic) leaching tests were conducted to study the leachability of the heavy metals in the fly ash.

\section{Materials and methods}

\subsection{Samples}

The fly ash was collected from various coal-fired plants in Xuzhou city and other plants in Shandong province. According to the boiler type and desulfurization technology, these samples could be divided into two types. The first type came from plants 


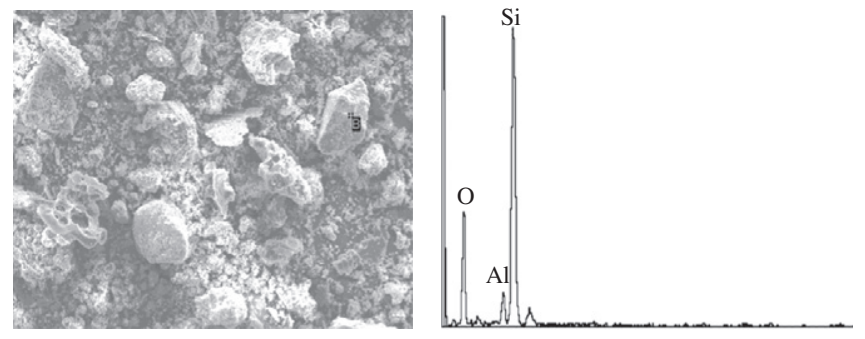

Fig. 1. Micromorphology of the quartz.

using a pulverized coal-fired boiler and limestone-gypsum wet flue gas desulfurization technology. The second group of samples came from plants using a circulating fluidized bed boiler, where a desulfurization agent is added during the progress of combustion.

\subsection{Analytical methods}

The micromorphology was observed using a Hitachi S-3500N Scanning Electron Microscopy/Energy Dispersive Spectroscopy (SEM/EDS) device. The mineral composition was measured with a D/Max-3B X-ray Diffraction Analyzer (XRD). Finally, Inductively Coupled Plasma Mass Spectrometry (ICP-MS) was used to analyze the concentrations of the elements.

\subsection{Leaching tests}

One representative sample was selected for the leaching tests. There were two leaching methods, a batch leaching test and a column leaching test. The batch leaching test is a simple test and provides qualitative predictive information on the leaching behavior of heavy metals. It may not adequately simulate long term and intermittent leaching conditions. However, the column leaching test monitors the heavy metal release over a long period and can identify temporal variations in the contaminant concentrations during the course of its transport through the fly ash [11,12].

In the batch leaching experiment, the samples were leached directly using deionised water. The mass of fly ash was $25 \mathrm{~g}$, the liquid/solid (L/S) ratios were 5 and 10 , and the oscillation frequency was set at $110 \pm 10 \mathrm{r} / \mathrm{min}$. The duration of mixing was $12 \mathrm{~h}$, after which the samples were allowed to stand for $12 \mathrm{~h}$ before the leachates were collected. The column leaching test was done at four different $\mathrm{pH}$ values with separate samples being continuously leached. The liquid/solid ratio was 5 . The leaching time was seven days, and the leachate was collected throughout the leaching time. For both methods, the leachate was filtered immediately through a 0.45 micron filter membrane and then analyzed by ICP-MS.

\section{Results and discussion}

\subsection{Mineral composition}

Coal contains many minerals which are composed of a variety of elements. The minerals change after the coal is fired and salic (mullite and quartz), ferruginous and calcareous minerals are produced [13-16].

Non-crystalline materials made up a large part of the mineral composition of the fly ash. Quartz and mullite were the main crystalline phases (point labeled B in Fig. 1), and other crystalline phases like illite, feldspar, calcspar, gypsum and hematite could also be found in the ash. Because of the high-temperature combustion in the pulverized coal-fired boiler, the quantity of the mullite in the ash from these plants to exceed that seen in plants using a circulating fluidized bed (Fig. 2a). Furthermore, the type of coal also influences the mineral composition of the ash. The circulating fluidized bed burns coal of low calorific value and adds the desulfurization agent during combustion, so the mineral composition of the fly ash from this boiler is complex and the number of species is very high (Fig. 2b).

All the fly-ash samples have oxides of silicon, aluminum and iron as the main chemical components of the ash. The sum of these components was more than $80 \%$ of the total. Silicon oxides were the main chemical component of the fly ash, and the content of aluminum and iron oxides were lower than that of silicon oxides. There were also other metal oxides present, such as $\mathrm{CaO}$. The content of $\mathrm{CaO}$ was less than $10 \%$ in the fly ash from these power plants, so the fly ash was classified as a low calcium ash.

\subsection{Heavy metals composition}

In addition to the normal elements, some trace elements were also included in the ash. The quantity of these trace elements varied considerably with different power plant. Some levels were capable of producing a cumulative toxic effect that could negatively affect the environment $[5,17,18]$. It was important to detect the types and contents of these heavy metals. Table 1 lists the elemental composition of fly ash (XZHX-FA, XZHM-FA) and bottom ash (XZHX-BA, XZHM-BA) from two different plants (XZHX, using the pulverized coal-fired boiler; XZHM, using the circulating fluidized-bed boiler).

The content of trace elements was significantly different in the different power plant ash. For the studied elements, the content of Ti was the highest in the fly ash, ranging from 5795 to $7382 \mu \mathrm{g} / \mathrm{g}$. The content of $\mathrm{Cd}$ was the lowest, ranging from 0.19 to $0.94 \mu \mathrm{g} / \mathrm{g}$. The contents of the elements in the fly ash were higher than those

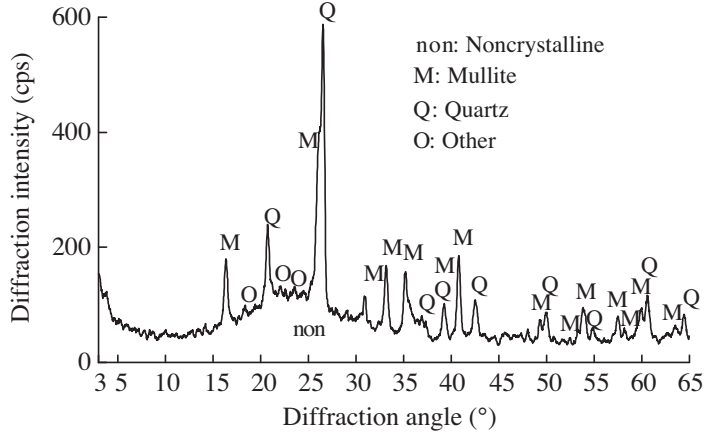

(a) Pulverized coal fired boiler

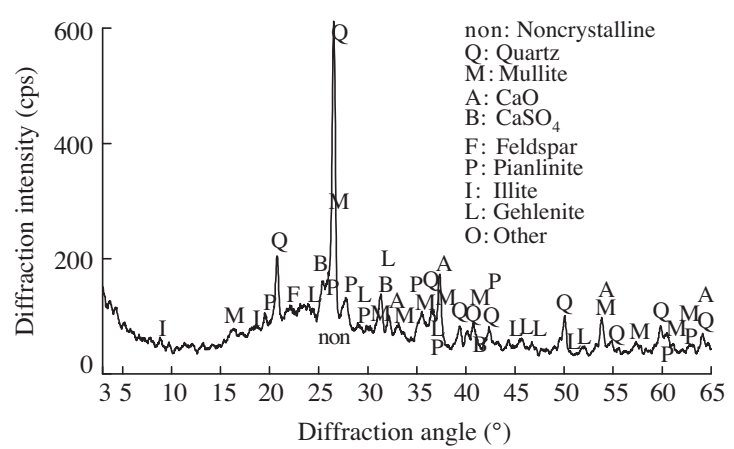

(b) Circulating fluidized bed boiler

Fig. 2. XRD spectra of the fly ash from two kinds of power plants. 
Table 1

Trace elemental analysis of the desulfurized ash $(\mu \mathrm{g} / \mathrm{g})$.

\begin{tabular}{|c|c|c|c|c|c|c|c|c|c|c|c|c|}
\hline Element & $\mathrm{Li}$ & $\mathrm{Be}$ & $\mathrm{Ti}$ & $\mathrm{Cr}$ & Mn & $\mathrm{Ni}$ & $\mathrm{Cu}$ & $\mathrm{Zn}$ & $\mathrm{Cd}$ & $\mathrm{Pb}$ & As & $\mathrm{Hg}$ \\
\hline XZHX-FA & 222.2 & 5.46 & 6919 & 85 & 265.1 & 34.54 & 67.68 & 107.10 & 0.66 & 68.29 & 291.7 & 7.6 \\
\hline XZHX-BA & 175.8 & 4.33 & 5415 & 76.65 & 367.1 & 25.21 & 44.49 & 37.09 & 0.10 & 19.37 & 291.7 & 7.6 \\
\hline XZHM-FA & 106.8 & 3.91 & 5795 & 104.30 & 447.5 & 38.70 & 53.24 & 80.71 & 0.27 & 44.65 & 309.5 & 8.6 \\
\hline XZHM-BA & 89.56 & 2.17 & 6076 & 105.30 & 176.6 & 26.70 & 39.01 & 86.69 & 0.07 & 36.43 & 309.5 & 8.6 \\
\hline
\end{tabular}

in the bottom ash, even though the samples came from the same plant. The metallic elements are easily enriched in the fly ash. Even when the ash came from the same type of boiler, but from different plants, the contents of the fly ash and bottom ash were different. $\mathrm{Pb}$, for example, the minimum value was $44.65 \mu \mathrm{g} / \mathrm{g}$, while the maximum value was $118.4 \mu \mathrm{g} / \mathrm{g}$, although both plants used a circulating fluidized bed. The differences are mainly due to the type of coal burnt in the power plants, the coal cleaning technology used, and the chemical properties of the elements themselves.

\subsection{Leaching tests}

Fly ash from the SDJN power plant was selected as the leaching sample in this study, because the flue-gas desulfurization and leaching effect is obvious in this power plant. This plant uses the circulating fluidized bed boiler.

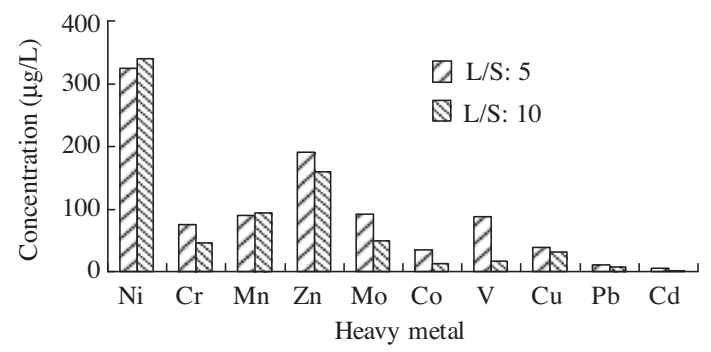

Fig. 3. Concentration of heavy metals in the leachates: batch leaching.

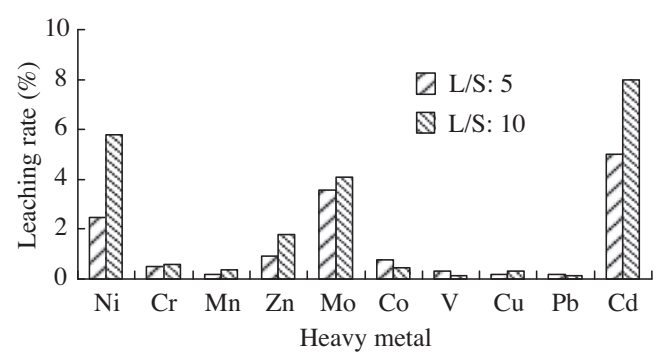

Fig. 4. Leaching rates of heavy metals: batch leaching.

\subsubsection{Batch leaching test}

In the batch leaching test, the concentrations of $\mathrm{Ni}$ in the leachates were the highest, while the concentrations of $\mathrm{Cd}$ were the lowest (Fig. 3). When the L/S ratio was increased, most of the heavy metal concentrations decreased. The concentrations of $\mathrm{Ni}, \mathrm{Cr}$ and Mo in the leachates each exceeded the national standard and had the potential to harm the environment.

However, the leaching rates of $\mathrm{Ni}$, Mo and $\mathrm{Cd}$ were higher than the other elements, and the rate for $\mathrm{Cd}$ was the highest, showed that Cd leached more easily from the fly ash (Fig. 4).

\subsubsection{Column leaching tests}

The column leaching test was done to analyze the leaching over time. In these trials $\mathrm{Ni}$ and $\mathrm{Zn}$ concentrations exceeded $100 \mu \mathrm{g} / \mathrm{L}$ in the leachates, and $\mathrm{Cr}$, Mo and Mn were between 40 and $100 \mu \mathrm{g} / \mathrm{L}$, $\mathrm{Co}, \mathrm{Cu}, \mathrm{Cd}, \mathrm{Pb}$ and $\mathrm{V}$ were all less than $20 \mu \mathrm{g} / \mathrm{L}$. Three different kinds of leaching curve were observed for these elements, see Fig. 5. The first type was a downward trending curve where the leached metal content decreased slightly with time. The harm caused to the environment by these elements will gradually diminish. $\mathrm{Ni}$ and $\mathrm{V}$ have this type of behavior. The second type was an increasing trending curve where the leached concentration increased with time. $\mathrm{Cr}$ and $\mathrm{Co}$ are part of this group. The last type was a fluctuating curve where the elemental concentrations fluctuated with time. The other concerned heavy metals examined belong in this group.

Different $\mathrm{pH}$ values affect leaching. The results showed that the lower $\mathrm{pH}$ values of the leaching solutions, the higher metal contents in the leachate. The reason for this might be that an acidic solution accelerates the mineral dissolution in the liquids.

\subsubsection{Contrasting the batch and column leaching tests}

Because the cumulative L/S ratio in the column leaching test was 5 , and because deionised water was used as the liquid medium in the batch leaching test, the batch leaching test with an L/S ratio of 5 is compared to the column leaching test using deionised water as the eluent.

The fly ash and deionised water were mixed completely and were in continuous contact during the batch leaching tests, while the fly ash was in gradual contact with the water with time during the column leaching tests, which is a dynamic process.

Comparing these two leaching tests, the results showed that the leaching rate was both higher and lower in the batch leaching
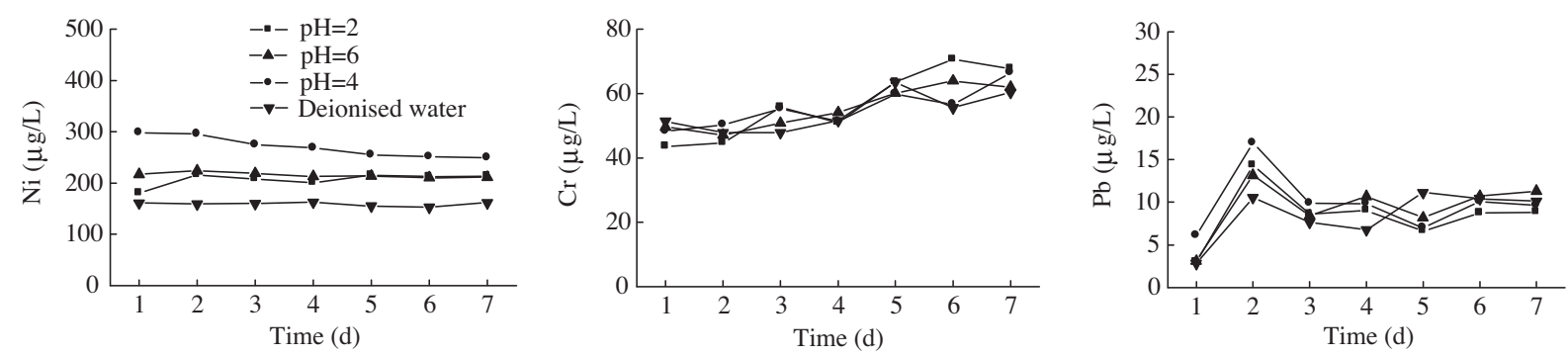

Fig. 5. Concentration of $\mathrm{Ni}, \mathrm{Cr}$ and $\mathrm{Pb}$ in leachates: continuous leaching. 


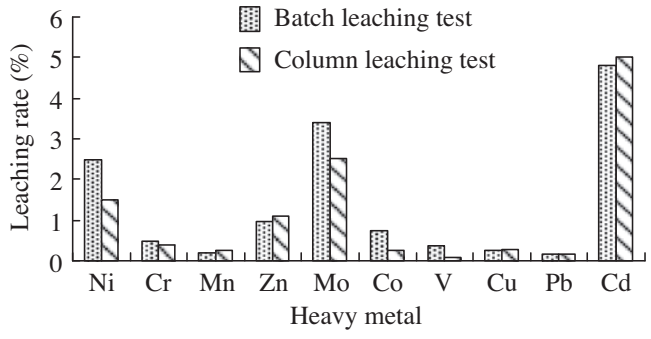

Fig. 6. Leaching rates of heavy metals from fly ash for different leaching tests.

test, depending upon the particular element. This was also true in the column leaching test. The batch leaching test promoted the leaching of $\mathrm{Ni}, \mathrm{Cr}$, Mo, Co and $\mathrm{V}$ from the fly ash, while the column leaching test promoted the leaching of $\mathrm{Mn}, \mathrm{Zn}, \mathrm{Cu}, \mathrm{Pb}$ and Cd (Fig. 6). In the batch leaching test, the fly ash and water contacted completely, and friction between solid particles and solid-water particles accelerated the dissolubility of the heavy metals. In the column leaching test, elemental concentration gradients existed between the fly ash and the deionised water could affect the release of the heavy metals.

Since the column leaching test was a better simulation of fly ash contact with rain or other liquids in a natural state, this method was used as a reference. However, the batch leaching test was mainly used to evaluate the maximum leaching toxicity of the solid.

\subsubsection{Effect of the leaching test on fly ash micromorphology}

The fly ash can be classified as spherical particles and irregular particles, according to the SEM analysis of their shapes and micromorphology $[13,19]$. The sample from this plant which did the leaching tests in my study was more irregular particles before the experimental leaching treatment.

After the leaching tests, parts of the components leached from the fly ash into the leachates and the microstructure of the particles changed. The solid samples from the column leaching test were dried and then analyzed by SEM. The samples were different in microstructure compared to the fly ash before the leaching test.

Fig. 7 shows the particle micromorphology before the leaching test. The particle size was larger (Fig. 7a) and the surface was coarse with a number of attached crystal clusters were (Fig. 7b). The EDS map from point B suggested the chemical compositions were mainly C, O, Al, Si and Ca (Fig. 7c).

When the fly ash was leached by deionized water, the particle size shrank compared to the original particles (Fig. 8a). This is a result of water erosion of the particles and the chemical dissolution of the elements. The surface of the particles was still coarse, but the quantity of crystals attached to the surface decreased (Fig. 8b). The elemental composition of corresponding points did not change too much, but Fe and $\mathrm{K}$ were detected (Fig. 8c).

Comparing Figs. 7a and 9a, the particle sizes were clearly reduced after leaching with the acid solution. Had the acidity of the leaching fluid been stronger, the particles size would possibly have been even smaller. The main reason for this size reduction was the strong chemical decomposition of the fly ash in the acidic solution.
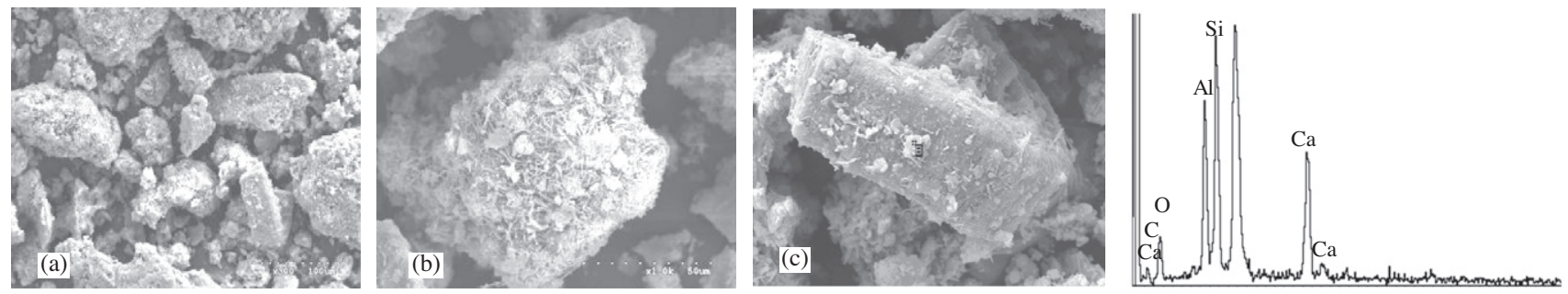

Fig. 7. SEM photomicrographs and EDS maps of fly ash before leaching.
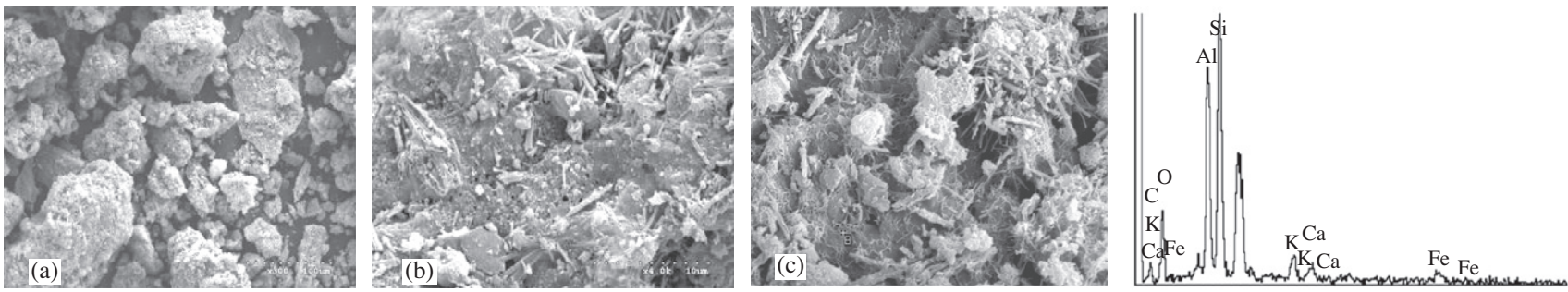

Fig. 8. SEM photomicrographs and EDS maps of fly ash after leaching with deionized water.
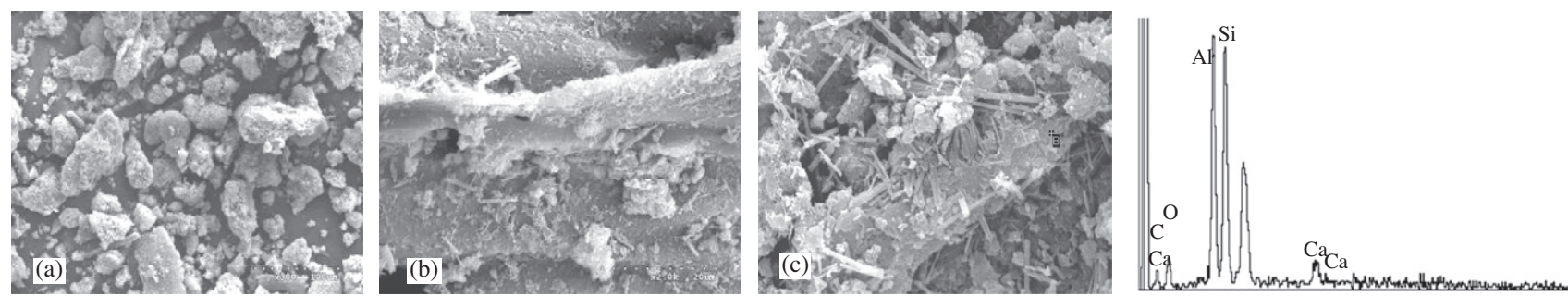

Fig. 9. SEM photomicrographs and EDS maps of fly ash after leaching with nitric acid solution at $\mathrm{pH}=2$. 


\section{Conclusions}

Fly ash from plants using the circulating fluidized bed contained more irregular particles. Because of the desulfurization technology used, the desulfurization product was mainly gypsum crystals in these samples. Samples from plants using a pulverized coal-fired boiler have more spherical particles. All samples contained more non-crystalline material in the ash, regardless of their origin. Crystalline phases like illite, feldspar, calcspar, gypsum and hematite could also be seen in the ash, along with the main minerals quartz and mullite. The heavy metals tested for all appeared in amounts above $1 \mu \mathrm{g} / \mathrm{g}$, except for $\mathrm{Cd}$. Ti had the highest content, which was above $7300 \mu \mathrm{g} / \mathrm{g}$, Most of the heavy metals tested were enriched in the fly ash. Heavy metals were hard to leach from the fly ash, but the concentration of $\mathrm{Ni}$ exceeded the standard using both the leaching methods. This might constitute a threat to the environment.

\section{Acknowledgments}

Financial support for this work, provided by the Europe-Asia Link (No. CN/ASIA-LINK/010 94556) and State Scholarship Fund of China Scholarship Council (No. 2010642035), are gratefully acknowledged.

\section{References}

[1] Goodarzi F. Characteristics and composition of fly ash from Canadian coal-fired power plants. Fuel 2006;85(10-11):1418-27.

[2] Tao D, Fan MM, Jiang XK. Dry coal flyash cleaning using rotary triboelectrostatic separator. Min Sci Technol 2009;19(5):642-7.

[3] Dai SF, Zhao L, Peng SP, Chou CL, Wang X, Zhang Y, et al. Abundances and distribution of minerals and elements in high-alumina coal fly ash from the Jungar Power Plant, Inner Mongolia, China. Int J Coal Geol 2010;81(4):320-32.

[4] Medina A, Gamero P, Querol X, Moreno N, León BD, Almanza M, et al. Fly ash from a Mexican mineral coal I: Mineralogical and chemical characterization. J Hazard Mater 2010;181(1):82-90.
[5] Mishra DP, Das SK. A study of physico-chemical and mineralogical properties of Talcher coal fly ash for stowing in underground coal mines. Mater Charact 2010;61(11):1252-9.

[6] Mishra SB, Langwenya SP, Mamba BB, Balakrishnan M. Study on surface morphology and physicochemical properties of raw and activated South African coal and coal fly ash. Phys Chem Earth Parts A/B/C 2010;35(1314):811-4.

[7] Senneca O. Burning and physicochemical characteristics of carbon in ash from a coal fired power plant. Fuel 2007;87(7):1207-16.

[8] Praharaj T, Powell MA, Hart BR, Tripathy S. Leachability of elements from subbituminous coal fly ash from India. Environ Int 2002;27(8):609-15.

[9] Skodras G, Grammelis P, Prokopidou M, Kakaras E, Sakellaropoulos G. Chemical, leaching and toxicity characteristics of CFB combustion residues. Fuel 2009;88(7):1201-9.

[10] Wang WF, Qin Y, Song DY, Wang KX. Column leaching of coal and its combustion residues, Shizuishan, China. Int J Coal Geol 2008;75(2): 81-7.

[11] Souhail RA, Jegadeesan G, Purandare J, Allen D. Leaching behavior of mineral processing waste: comparison of batch and column investigations. J Hazard Mater 2010;153(3):1088-92.

[12] Barna R, Rethy Z, Tiruta-Barna L. Release dynamic process identification for a cement based material in various leaching conditions. Part I. Influence of leaching conditions on the release amount. J Environ Manage 2005;74(2):141-51.

[13] Liu YS, Zheng LT, Li XD, Xie SD. SEM/EDS and XRD characterization of raw and washed MSWI fly ash sintered at different temperatures. J Hazard Mater 2009;162(1):161-73.

[14] Koukouzas N, Ward CR, Papanikolaou D, Li ZS, Ketikidis C. Quantitative evaluation of minerals in fly ashes of biomass, coal and biomass-coal mixture derived from circulating fluidised bed combustion technology. J Hazard Mater 2009;169(1):100-7.

[15] Font O, Moreno N, Querol X, Izquierdo M, Alvarez E, Diez S, et al. X-ray powder diffraction-based method for the determination of the glass content and mineralogy of coal (co)-combustion fly ashes. Fuel 2010;89(10):2971-6.

[16] Fu XR, Zhai JP, Li FH, Sheng GH. Research on the physical and chemical properties of desulfurized fly ash drained from Jinling power plant. Fly Ash Comprehensive Utilization 2005;2:14-6.

[17] Bhanarkar AD, Gavane AG, Tajne DS, Tamhane SM, Nema P. Composition and size distribution of particules emissions from a coal-fired power plant in India. Fuel 2008;87(10-11):2095-101.

[18] Fedje KK, Rauch S, Cho P, Steenari BM. Element associations in ash from waste combustion in fluidized bed. Waste Manage (Oxford) 2010;30(7):1273-9.

[19] Zhang CF, Yao Q, Sun JM. Characteristics of particulate matter from emissions of four typical coal-fired power plants in China. Fuel Process Technol 2005;86(7):757-68. 